\title{
Análise de cobertura jornalística: um protocolo metodológico
}

Gislene Silva $^{1}$

Flávia Dourado Maia²

Resumo: O acontecimento jornalístico pode ser observado e analisado por meio das marcas que o processo de produção da notícia deixa no próprio produto acabado. Retomando apontamentos sobre alguns dos entraves teórico-metodológicos que se interpõem à ampliação e ao aprimoramento das teorias do jornalismo, e sobre a necessidade de abordagens menos fragmentárias do fenômeno jornalístico, apresentamos um protocolo de análise de cobertura jornalística com o objetivo de possibilitar a apreensão do acontecimento jornalístico numa instância localizada entre o trabalho de bastidores da redação e as análises subseqüentes do conteúdo temático e do discurso no e sobre o mesmo acontecimento. A base teórica buscamos em Quéré, quando problematiza lugares da mídia para pensar o acontecimento ${ }^{3}$.

Palavras-chave: acontecimento jornalístico, cobertura jornalística, produção jornalística, metodologia da pesquisa.

Abstract: The journalistic event can be observed and analysed through the signs the process of news production leaves in its own finished product. Considering observations on some of the theoretical and methodological obstacles placed in the improvement and in the expansion of journalism theories and on the neeed for less fragmented approaches of the journalistic phenomenon, we present a protocol of analysis of news coverage in order to understand the journlistic event in the instance located between the work behind the scenes of journalism and the subsequent analysis of the thematic content and of the discourse in and on the same event. The theoretical basis was Quére, when the author discusses the position of media to think the event.

Keywords: journalistic event, journalistic coverage, journalistic production, research methodology. 
Ao tratar da dupla natureza do acontecimento, como fato e sentido, Louis Quéré levanta questões a respeito do lugar da mídia na configuração das coisas que acontecem, introduzindo reflexões sobre o acontecimento jornalístico. Na contraposição e diálogo entre G. H. Mead e H. Arendt, Quéré explicita a dualidade do acontecimento, que se daria "tanto a explicação causal do acontecimento e a construção do seu passado e do seu futuro, como o seu poder de esclarecimento e a fonte de inteligibilidade que ele constitui." (QUÉRÉ, 2005, p. 6). Na observação de J. Rebelo, dessa dualidade resulta que o acontecimento seja simultaneamente explicável e explicativo. Explicável através da produção de narrativas, de estórias que origina. Explicativo pelo poder que transporta, enquanto revelador daquilo que (trans)forma, ou pode (trans)formar, nas pessoas e nas coisas (REBELO, 2006, p. 19). Queremos dizer, como pressuposto central deste trabalho, que muito do explicável dos acontecimentos publicados na imprensa poderia ser investigado não exclusivamente nas narrativas produzidas, mas também no que poderíamos chamar de narrativas da própria produção do acontecimento jornalístico, ou seja, nas estratégias e técnicas do processo produtivo da notícia.

De início, estudar o acontecimento jornalístico exige problematizar técnicas e métodos de investigação empregados nos estudos sobre a mídia noticiosa. Entre os principais impasses para a qualificação das investigações desenvolvidas na pesquisa em jornalismo podemos destacar a ausência de menção aos métodos empregados e as frequentes confusões entre opções teóricas e opções metodológicas; as dificuldades de sistematizar os procedimentos metodológicos e as inconsistências entre a metodologia pretendida e a metodologia praticada (SILVA, 2008); a "insipiência do discurso sobre os métodos" (QUADROS e BENETTI, 2007); a escassez de metodologias próprias, que permitam estudar o jornalismo como objeto científico particular; a preponderância de problemas de pesquisa formulados a partir do arcabouço teórico de outras áreas; o não desenvolvimento de estratégias metodológicas híbridas ou adaptadas para o estudo do jornalismo, que consigam estabelecer 
um diálogo entre a pesquisa acadêmica e a prática profissional (GADINI, 2005; STRELOW, 2008; HOHLFELDT e STRELOW, 2007).

O diagnóstico esboçado por esses autores expõe a fragilidade da dimensão metodológica das pesquisas em jornalismo e sinaliza as dificuldades em eleger, criar e adaptar metodologias nesta área de pesquisa, comprometendo a obtenção de resultados válidos para o fortalecimento das bases teórico-epistemológicas do jornalismo. Sem dúvida, desenvolver estratégias metodológicas próprias do campo passa a ser crucial para consolidar as pesquisas em jornalismo. Mas não se pode desconsiderar que direcionar o debate tendo esse norteador como um imperativo leva a que se tome autonomia por isolamento e que se caminhe na contramão da interdisciplinaridade, ignorando contribuições que outros campos do conhecimento oferecem para o estudo do fenômeno jornalístico. O desafio maior que se coloca para os pesquisadores, portanto, é o de expandir o leque de possibilidades teórico-metodológicas, visando novas alternativas ou tornando as já existentes mais apropriadas para lidar com questionamentos e demandas específicas do campo. No caso particular de estudos que tomam textos jornalísticos impressos como objeto empírico, o que se nota é uma ilusória pluralidade metodológica, cogitada, mas não alcançada. Trata-se, como observa Silva, de uma polifonia metodológica aparente (2008, p. 9), caracterizada pela utilização de métodos com nomenclaturas distintas, associados a intenções variadas, mas frequentemente apoiados em princípios teórico-metodológicos que convergem para a Análise do Discurso (AD) ou para a Análise de Conteúdo $(A C)^{4}$. De acordo com a autora, essa repetição de fórmulas investigativas atuaria no sentido de encobrir a carência de metodologias mais apropriadas para investigar o jornalismo. Pode-se dizer, assim, que a escolha pela $A C$ e $A D$ - incluindo suas derivações - se dá em um hiato metodológico: perante a falta de opções de métodos, os pesquisadores acabariam por recorrer, de forma pouco reflexiva e criteriosa, às ferramentas de que dispõem e que são tradicionalmente utilizadas para investigar problemáticas adjacentes àquelas que de fato Ihes interessam. 
Tal recorrência comum à $A C$ e à $A D$ pode ser associada, também, ao locus do objeto empírico. Segundo Silva (2008), há, nos estudos dos produtos, indícios da preponderância da análise da mensagem sobre as demais etapas do processo jornalístico, tendência que estaria ligada, de um lado, à pouca tradição de pesquisas de recepção e produção jornalística no país; e, de outro, a fatores de ordem mais pragmática - como acesso ao objeto, custos e tempo de duração da investigação -, que tornariam o trabalho com textos jornalísticos mais conveniente ${ }^{5}$. Por trás dessas opções estaria ainda uma razão de ordem epistemológica: a tendência à fragmentação do processo jornalístico segundo o esquematismo dos modelos de comunicação tradicionais, que separam produção (emissão), produto (meio/mensagem) e consumo (recepção) em categorias estanques, como apontam Escosteguy (2007) e Silva (2008).

Em resumo, a falta de preocupação com metodologias mais apropriadas conduz à repetição de fórmulas metodológicas sem as considerações e adaptações necessárias. Aplicadas indistintamente a perguntas de pesquisa variadas e com escopos os mais diversos, essas fórmulas acabam por compor um quadro limitado de respostas, quase sempre circunscritas ao domínio do meio/mensagem, e também por encobrir a deficiência das metodologias de pesquisa em jornalismo.

Com o objetivo de chamar atenção para a pertinência de abordagens menos fracionárias do jornalismo como objeto de estudo, queremos dar relevo aqui à construção do acontecimento jornalístico pelas estratégias e técnicas de apuração e composição visíveis no texto. Para isso estamos propondo um protocolo metodológico de análise de cobertura jornalística em textos impressos, capaz de mostrar a viabilidade de se investigar no produto publicado elementos do processo de elaboração do acontecimento como notícia, um método de investigação complementar aos estudos de newsmaking realizados nas redações e às análises de conteúdo e de discurso dos textos. Trata-se de inversão inspirada também em Quéré. Só que não estamos preocupadas, por enquanto, em tematizar o acontecimento jornalístico, voltando ao contexto que o produziu 
para esclarecê-lo, e nem focadas na ação desse acontecimento em modificar inteligibilidades, projetando nova luz sobre o que the precedeu ou estar por vir. A significação constitui o próprio contexto de sentido. E esse contexto de sentido pode começar a ser observado, antecipadamente, nas decisões editoriais que deixam suas marcas no produto, no acontecimento publicado.

\section{O processo no produto}

O desenvolvimento de um método específico para estudar a produção a partir do produto requer, primeiramente, a adoção de uma perspectiva teóricometodológica mais aberta, que não restrinja o olhar sobre o objeto às diretrizes do modelo fragmentário de processo jornalístico, no qual produção, produto e recepção são tomados como categorias estanques. Mais além, requer que se desvincule a noção de produto da noção de mensagem e que se rompa com a matriz conceitual que tende a reduzir uma à outra.

As limitações dos enfoques fracionários do jornalismo já vêm sendo apontadas por autores filiados aos Estudos Culturais, que reivindicam uma abordagem mais global e totalizante do processo jornalístico, como fazem Escosteguy (2007), Strelow (2007) e Santi (2010). Inspirados no circuito cultural de Richard Johnson $(2000)^{6}$, esses pesquisadores propõem um método para analisar cada um dos momentos do processo jornalístico, procurando explorar as conexões entre um segmento e outro. O recorte epistemológico demarcado aí representa um passo relevante para as pesquisas em jornalismo; contudo, investe ainda em cada ponto do circuito separadamente: a produção continua a ser encarada como uma instância circunscrita às rotinas produtivas, o produto segue sendo associado quase que exclusivamente à mensagem e a recepção permanece atrelada prioritariamente à construção de sentidos.

Insistir no modelo segmentário de processo jornalístico implica corroborar a ideia de que cada momento do circuito revela dados somente sobre si mesmo, ou, conforme afirma Johnson, que "os processos desaparecem nos produtos" de 
tal forma que "as condições de produção não podem ser inferidas simplesmente examinando-os [os produtos] como textos" (JOHNSON, 2000, p. 33). Por isso, mais pertinente para a proposta metodológica aqui pretendida - um protocolo de análise de cobertura jornalística - parece ser um posicionamento à margem desse modelo esquemático, que possibilite "pensar fora da lógica das etapas, para além dos fragmentos recortados do circuito" (SILVA, 2008, p. 9). Na contramão do que afirma Johnson (2000), defende-se aqui a hipótese de que, em se tratando de textos jornalísticos, o processo nem sempre desaparece no produto. Sustentamos que, em geral, o processo manifesta-se no produto, em maior ou menor medida. Partindo dessa hipótese, entendemos que, para compreender o processo jornalístico de forma menos fragmentária, é não só necessário, como também viável, pesquisar "como em um único ponto do circuito escolhido como objeto de trabalho podemos localizar informações que mostrem os demais. (...) Além de perceber o processo de produção da notícia no texto, poderíamos investigar e verificar o receptor na produção, a produção na recepção" (SILVA, 2008, p. 10).

Em revisão de trabalhos que traçam o perfil das pesquisas em jornalismo no Brasil, Silva (2008) ressalta que muitos dos estudos dedicados a produtos tratam de aspectos do processo de cobertura jornalística. Contudo, ainda segundo a autora, apesar de terem como foco elementos da produção, tais estudos geralmente apresentam como opção metodológica a Análise de Discurso ou a Análise de Conteúdo.

É o caso de trabalhos que revelam, e revelam bem, via texto, as condições de apuração, como, por exemplo, se a matéria vem assinada ou não, se de correspondente ou de agência, se somente com fontes oficiais etc. Dados que mostram muito mais do processo produtivo, e que por isso o protocolo metodológico adotado ali não deveria se vincular à análise de discurso - método/teoria dos mais referenciados recentemente (SILVA, 2008, p. 9).

O protocolo de análise que propomos trata, então, da sistematização e formalização de um caminho investigativo já trilhado por alguns pesquisadores, 
ainda que de maneira desordenada, descontínua, metodologicamente inadequada ou mesmo inconsciente. Ao comentar a quantidade expressiva de trabalhos científicos que vêm se valendo de produtos para investigar o processo de produção, Silva atenta para a necessidade de se repensar os métodos tradicionalmente utilizados nesses casos e de se desenvolver uma ferramenta metodológica voltada para esse fim, "como seria o caso de uma metodologia própria para a análise de cobertura jornalística, quer dizer, quando o texto publicado pode revelar aspectos do processo produtivo da notícia, sem passar pela estreita compreensão do que entendemos por newsmaking" (SILVA, 2008, p. 10).

Sabe-se, de saída, que nem todos os aspectos implicados no processo produtivo podem ser acessados através do produto. Após ser recortado em torno da produção, o objeto jornalismo continua a desdobrar-se em diferentes esferas de análise, como demonstra Guerra (2000). De acordo com o autor, o conjunto de procedimentos e métodos específicos da prática jornalística - o fator operacional - pode ser abordado a partir de três dimensões: a (1) normativa, a (2) técnica e a (3) organizacional. A primeira refere-se às determinações legais e aos princípios éticos a serem observados no exercício profissional, que funcionam como um parâmetro de qualidade e como um instrumento pedagógico. A segunda subdivide-se em (a) técnico-procedimental, ligada à atuação dos jornalistas no sentido de materializar os preceitos normativos que regem as relações entre sujeitos (jornalistas entre si, jornalistas com as fontes, jornalistas com o público e jornalistas com as pessoas-tema das notícias); e (b) técnicometodológica, relativa ao processo de composição do produto propriamente dito, ou seja, ao conjunto das ações implicadas nas relações sujeito-objeto (jornalistaacontecimento e jornalista-produto), como estratégias de apuração, práticas de captação das informações, elaboração e formatação do texto jornalístico e apresentação do produto no conjunto do veículo. A terceira, por fim, diz respeito à racionalização do trabalho no contexto geral da organização jornalística e pode 
ser traduzida nas rotinas produtivas - pauta, reportagem, edição, veiculação, prazos, cronogramas, quadro de funcionários, divisão e atribuição de tarefas, demandas comerciais, entre outros.

Tomando a categorização de Guerra (2000) como referência, é possível demarcar a área de abrangência do protocolo de análise de cobertura jornalística. A dimensão normativa não pode ser abordada pelo método por centrar-se no deve-ser - numa projeção de modelo ideal de jornalismo, que não corresponde, necessariamente, às práticas produtivas empregadas no dia-a-dia da profissão. A dimensão técnico-procedimental também não se situa dentro do campo de alcance do protocolo por envolver dilemas e escolhas de natureza ética concernentes às relações entre sujeitos, elementos que até poderiam ser inferidos com base no produto, mas que dificilmente estariam explícitos a ponto de serem objetivamente identificados ${ }^{8}$. As demais dimensões se mesclariam no que propomos como método de análise de cobertura. Embora as formas como as organizações jornalísticas administram e planejam internamente as atividades produtivas sejam mais adequadamente captadas por meio do acompanhamento das rotinas de trabalho, ou entrando em contato com os profissionais da redação, elas deixam suas marcas no produto pronto. Além das marcas da dimensão organizacional, também as da dimensão técnico-metodológica são perceptíveis no produto, naqueles aspectos diretamente vinculados às técnicas e às práticas específicas de produção do material informativo.

Ao reconstituir, através de marcas deixadas no produto, o caminho percorrido pelo jornalista e pelo veículo para apurar e relatar as informações, o método que propomos quer observar as estratégias de cobertura expressas no material jornalístico. Por isso, a abrangência do protocolo varia em proporção direta à manifestação do modus operandi no produto analisado. Esse atrelamento sinaliza, a um só tempo, para um ponto fraco da proposta metodológica, a dependência do grau de exposição do processo produtivo no texto, e para um de seus pontos fortes, a propriedade para fomentar debates acerca da (a) 
utilização de procedimentos sistemáticos na apuração de informações e da (b) explicitação de tais procedimentos segundo a regra da transparência.

O protocolo ajuda a pensar, a identificar e a tipificar as especificidades da atividade jornalística, mapeando tendências e possíveis lacunas na obtenção, averiguação e apresentação das informações. Não avaliamos que a explicitação do método de trabalho jornalístico seja viável somente via produtos e meios alternativos (cf. MAIA, 2008). Preferimos concordar com Kovach e Rosenstiel (2004, p. 112), quando enfatizam que a prática jornalística alicerça-se sobre a "disciplina da verificação", isto é, sobre um método singular para abordar os acontecimentos, acessar fontes, checar informações e desenvolver relatos claros, que pode e deve vir à tona nos produtos, revelando ao público o máximo possível sobre os procedimentos de trabalho adotados na cobertura. Eles mencionam uma série de aspectos técnicos do processo produtivo que podem ser explicitados - e, logo, estudados empiricamente - em produtos jornalísticos comuns: (1) fontes de informação consultadas; (2) tendência ao jornalismo declaratório, ou seja, à transposição exagerada de falas; (3) preponderância de análises e interpretações sobre a busca de fatos novos; (4) recorrência do denuncismo - quando o jornal publica suspeitas e alegações sem sustentálas em uma investigação própria; (5) recurso abusivo ao off; (6) emprego de métodos não-ortodoxos de apuração, como câmera escondida, disfarce e infiltração; (7) freqüência da apuração de segunda mão; (8) predomínio de fontes oficiais; entre outros. Convertidos em categorias e variáveis de análise, os aspectos levantados por Kovach e Rosenstiel (2004) contribuem para estruturar o protocolo apresentado aqui.

\section{Protocolo metodológico de Análise de Cobertura Jornalística}

O protocolo de análise de cobertura jornalística volta-se para textos jornalísticos impressos e informativos ${ }^{9}$. O método organiza-se em três níveis analíticos - $\left(1^{0}\right)$ marcas da apuração, (20) marcas da composição do produto e (30) aspectos da caracterização contextual. Cada um deles olha para o objeto 
de estudo a partir de uma lente diferente. O primeiro, mais específico, funciona como uma teleobjetiva: recai exclusivamente sobre a matéria jornalística - tomada de forma isolada -, explorando indícios do método de apuração e da estratégia de cobertura em close-up. O segundo corresponde a uma lente normal, de alcance médio, pois que oferece uma visão um pouco mais aberta do objeto, agora enfocando não só o texto, mas o conjunto amplo do produto, como localização na página, diagramação, foto etc. E o terceiro atua como uma grande angular - não capta detalhes, mas oferece um plano geral do objeto, captando aspectos da dimensão organizacional e do contexto sócio-históricocultural em que se insere a produção jornalística.

Cabe ressalvar que os dois primeiros níveis constituem a espinha dorsal do protocolo, uma vez que são fundamentais para a análise do processo produtivo a partir do produto e que podem ser suficientemente contemplados por meio da definição de categorias. Já o último nível é complementar, visto que tem por objetivo contextualizar os dados obtidos nos níveis 1 e 2 , além de requerer a combinação com outros métodos, como newsmaking tradicional ou survey.

\section{$1^{0}$ nível - Marcas da apuração}

1) Assinatura:

- Local (repórter da matriz da redação);

- Correspondente;

- $\quad$ Enviado especial;

- Colaborador;

- Agência de notícias;

- Não assinado.

2) Local de apuração/acesso do jornalista ao local do acontecimento: é preciso buscar vestígios desse item no contexto geral da notícia, mas a assinatura (item 1) pode ajudar. 
- Interno (redação) ou indefinido: quando não há, no texto, indícios de que o jornalista tenha se deslocado para o local do acontecimento;

- Externo: quando o jornalista faz a apuração in loco. Trata-se do local específico do acontecimento ou da cidade, estado, país ou continente em que o fato ocorre.

Entre as questões que se pode levantar estão: algum profissional da redação foi mobilizado? Foi preciso deslocar alguém? Em que dia em relação ao acontecimento a pessoa foi deslocada? O veículo dispõe de redações/sucursais em diversos locais? O veículo publica textos que não foram produzidos por jornalistas da redação? O veículo conta com marcadores ou setoristas? Tais aspectos ajudam a entender, por exemplo, por que determinados acontecimentos e/ou locais foram cobertos e outros deixados de fora e como essas estratégias moldam os acontecimentos cobertos.

3) Origem da informação: trata das fontes consultadas. Como há inúmeras formas de classificá-las, sugere-se aqui uma tipificação que mescla três critérios principais ${ }^{10}$ : (a) a forma como a informação foi obtida (direta ou indiretamente); (b) a natureza das fontes (humana, documental ou eletrônica); e (c) a posição das fontes no contexto dos acontecimentos (no caso de fontes humanas), ou seja, o lugar a partir do qual a fonte fala para dar as informações. Acredita-se que tais critérios atendem bem ao objetivo de analisar os esforços de apuração dos jornalistas.

- Informações de primeira mão: são obtidas diretamente pelos autores do texto e podem ser fornecidas por fontes de naturezas diversas (inclusive por meio de declarações publicas em coletivas de imprensa e eventos em geral), entre as quais destacam-se:

- Fontes do poder público: gozam do status de Estado - são ligadas diretamente aos três poderes, ao Ministério Público ou a autarquias (ex.: polícia, exército, deputado, prefeito, Ibama, Funai, IBGE e Petrobrás). (Não incluídas as assessorias de imprensa, advogados ou familiares que representam ou falam em nome destas fontes); 
- Fontes institucionais: são ligadas a empresas privadas, hospitais, associações, ONGs, partidos políticos, movimentos sociais, sindicados, fundações etc., que estão envolvidas nos acontecimentos. Também não inclui assessorias de imprensa, advogados ou familiares que representam ou falam em nome destas fontes;

- Fontes cidadãs: pessoas que testemunham fatos, fornecem informações ou dão sua opinião na condição de cidadãos afetados pelos acontecimentos;

- Fontes especializadas/comentadores: especialistas ou pessoas com autoridade suficiente para dar sua opinião sobre o assunto, interpretar os acontecimentos e fornecer informações que ajudam a contextualizar os fatos;

- Assessoria de imprensa: profissionais especializados e autorizados a falar com os jornalistas em nome de uma pessoa ou instituição;

- Fontes não-convencionais: a informação pode ser claramente identificada como sendo de uma fonte específica, mas sua identidade não é revelada. Caso de fontes anônimas, que caracteriza o uso do off;

- Recursos alternativos (câmera escondida, disfarce, infiltração etc.): embora não constituam uma fonte propriamente dita, tornam possível ao jornalista ter um acesso direto, minimamente mediado, às informações.

- Informações de segunda mão: são obtidas por terceiros e reproduzidas pelos autores do texto. Geralmente são fornecidas por:

- Agências de notícias: quando não se publica o texto da agência na íntegra, mas utilizam-se informações repassadas por ela;

- Outros veículos jornalísticos: as informações são extraídas de textos publicados em outros veículos; 
- Publicações científicas: informações de caráter científico retiradas de publicações legitimadas pela comunidade científica;

- Documentos impressos e eletrônicos: estatísticas, bases de dados, documentos públicos, pessoais e institucionais, arquivos históricos etc.;

- Ciberespaço: informações obtidas na internet, que podem ou não ser respaldadas por uma instituição ou instância do poder público e podem ou não ser imputadas a uma pessoa específica ${ }^{11}$;

- Reedição: quando se utilizam informações de segunda mão de origens diversas, especialmente de agências de notícias e de outros veículos, para produzir um texto próprio;

- Republicação: publicação de conteúdo de outros veículos, como é o caso da Carta Capital, que publica textos traduzidos da revista inglesa The Economist.

É importante procurar traços de material fornecido pelas assessorias de imprensa e registrar se o jornalista-narrador também atua como fonte ao utilizar informações que observou diretamente.

\section{$2^{\circ}$ nível - Marcas da composição do produto}

4) Gênero jornalístico/natureza do texto informativo:

- Nota;

- Notícia;

- Fotonotícia/fotolegenda;

- $\quad$ Entrevista;

- Reportagem;

- $\quad$ Reportagem especial/dossiê. 
5) Localização do texto no veículo/destaque:

- Página par ou ímpar

- Quadrante superior direito/esquerdo, inferior direito/ esquerdo;

- Metade superior ou inferior;

- Página inteira;

- Várias páginas (quantas).

- Editoria/caderno ou seção.

- Manchete, chamada de capa ou apenas texto.

6) Recursos visuais/adicionais: próprios de agência de notícias, de assessoria de imprensa ou de outra fonte (conforme a classificação do item 3);

- Gráfico ou tabela;

- Boxe;

- Infográfico;

- Imagem não-fotográfica (como ilustrações e montagens);

- Fotografia.

\section{$3^{\circ}$ nível - Aspectos do contexto de produção}

7) Caracterização contextual:

- Contexto interno: caracterização visual, editorial e organizacional do veículo/empresa. Pode incluir aspectos como perfil da redação, rotinas produtivas, orientações editoriais expressas, tiragem, área de abrangência, estrutura de produção própria, público-alvo, formato do produto, se produto segmentado/dirigido.

- Contexto externo: caracterização do tema/acontecimento/assunto específico da cobertura e da conjuntura sócio-histórico-cultural envolvente. 
Todos esses elementos da cobertura jornalística observados e analisados podem demonstrar como o acontecimento foi sendo apreendido, e daí pode-se verificar ou inferir as relações entre o modo como foi coberto o acontecimento e sua configuração final como acontecimento narrado, construído para ser lido.

\section{Considerações finais}

O protocolo de análise de cobertura jornalística pode ser usado para investigar como um determinado veículo estrutura a cobertura de assuntos em geral ou de acontecimentos específicos, verificando as marcas das técnicas e estratégias de apuração e composição da matéria jornalística a respeito de qualquer tema/assunto/acontecimento. Também é indicado para comparar tais marcas e estratégias em diferentes veículos, seja sobre um caso particular no momento presente ou temáticas que se repetem. Além disso, comporta o estudo de processos produtivos do passado, bem como de transformações na cobertura ao longo do tempo, sobretudo quando o corpus envolve um recorte temporal extenso.

Quando há ênfase no contexto sócio-histórico-cultural, possibilita relacionar as estratégias de apuração à influência de forças conjunturais, como seria o caso de estudar textos jornalísticos produzidos durante a ditadura militar, períodos eleitorais, grandes eventos, desastres naturais, guerras, entre outros. $\mathrm{E}$, se combinado com entrevistas em profundidade ou survey, o protocolo permite, ainda, confrontar o que os jornalistas dizem a respeito do que fazem com o que se mostra visível na publicação.

Por fim, cabe voltar à idéia da Análise de Cobertura Jornalística (ACJ) como mais uma opção metodológica junto à Análise de Conteúdo, focada mais nas temáticas, e à Análise de Discurso, atenta à produção de sentidos dos textos. Um método para investigar o produto jornalístico impresso - podendo ser adaptado para cobertura radiofônica ou televisa - e, como nos interessa 
agora, para estudar a configuração do acontecimento jornalístico pelas estratégias e técnicas de apuração, composição e disposição para a leitura. Como destaca Quéré, os media têm papel decisivo "enquanto suportes, por um lado, da identificação e da exploração dos acontecimentos, por outro, do debate público através do qual as soluções são elaboradas ou experimentadas" (QUÉRÉ, 2005, p. 22). O que propomos aqui é trilha pequena frente à grandiosidade desse percurso de duplicidade proposto por Quéré, aquela encruzilhada entre "compreender o acontecimento, compreender segundo o acontecimento". Mas não deixa de ser um dos acessos à complexidade do que nomeamos como acontecimento jornalístico. 


\section{Referências}

ESCOSTESGUY, Ana Carolina. "Circuitos de cultura/circuitos de comunicação: um protocolo analítico de integração da produção e da recepção". Comunicação, Mídia e Consumo, São Paulo, vol. 4, n. 11, nov. 2007, p. 115-133.

GADINI, Sérgio. "Dilemas da pesquisa no jornalismo contemporâneo: da abrangência midiática à ausência de métodos específicos de investigação". III Encontro Nacional de Pesquisadores em Jornalismo, Florianópolis, 2005. Anais eletrônicos.

GUERRA, Josenildo. "Ensaio sobre o jornalismo: um contraponto ao ceticismo em relação à tese de mediação jornalística". IX Encontro Anual da Associação Nacional dos Programas de Pós-Graduação em Comunicação, Porto Alegre, 2000. Anais eletrônicos.

HOHLFEDLT, Antonio; STRELOW, Aline. "Metodologias de pesquisa. O estado da arte no campo do Jornalismo: os núcleos de pesquisa da Intercom". V Encontro Nacional de Pesquisadores em Jornalismo, Aracaju, 2007. Anais eletrônicos.

JOHNSON, Richard. "O que é, afinal, Estudos Culturais?". In: SILVA, Tomas (Org.). O que é, afinal, Estudos Culturais? Belo Horizonte: Autêntica, 2000, p. 7-131.

KOVACH, Bill; ROSENSTIEL, Tom. Os elementos do jornalismo: o que os jornalistas devem saber e o público exigir. São Paulo: Geração Editorial, 2004.

LAGE, Nilson. A reportagem: teoria e técnica de entrevista e pesquisa jornalística. Rio de Janeiro: Record, 2001.

MACHADO, Marcia Benetti; LAGO, Cláudia. Metodologias de pesquisa em jornalismo. Petrópolis: Vozes, 2007.

MAIA, Marta Regina. "A regra da transparência como elementos de democratização no processo da produção jornalística". Brazilian Journalism Research, Brasília, vol. 1, n. 1, p. 213-152, semestre 2, 2008.

PONTE, Cristina. Crianças em notícia: a construção da infância pelo discurso jornalístico (1970-2000). Lisboa: ICS, 2005.

QUÉRÉ, Louis. "Entre facto e sentidos: a dualidade do acontecimento". Revista Trajectos, Lisboa, n.6, p. 59-76, 2005. 
REBELO, José. "Prolegómenos à narrativa mediática do acontecimento". Revista Trajectos, Lisboa, no. 8-9, p. 17-27, 2006.

SANTI, Vilso Junior. "A pesquisa qualitativa no circuito das notícias". XI Congresso de Ciências da Comunicação na Região Sul, Novo Hamburgo, 2010. Anais eletrônicos.

SILVA, Gislene. "Problemática metodológica em jornalismo impresso". Rumores - Revista Online de Comunicação, Linguagem e Mídias. São Paulo, vol. 1, n. 1, jul.-dez. 2008.

SOUSA, Jorge Pedro. Elementos de teoria e pesquisa: da comunicação e da mídia. Florianópolis: Letras Contemporâneas, 2004.

STRELOW, Aline. "Análise Global de Processos Jornalísticos". V Encontro Nacional de Pesquisadores em Jornalismo, Aracaju, 2007. Anais eletrônicos.

. "A discussão metodológica e a construção do campo jornalístico". VI

Encontro Nacional de Pesquisadores em Jornalismo, São Bernardo do Campo, 2008. Anais eletrônicos.

1 Professora no Departamento de Jornalismo da UFSC e coordenadora do Programa de Pós-Graduação em Jornalismo. Doutora pelo Programa de Estudos Pós-Graduados em Ciências Sociais (Antropologia) da PUC de São Paulo.

2 Jornalista pela Universidade Federal de Viçosa, especialista em jornalismo científico pela Unicamp e mestranda do Programa de Pós-Graduação em Jornalismo da Universidade Federal de Santa Catarina.

3 Este texto teve sua primeira versão apresentada no VIII Encontro Nacional de Pesquisadores em Jornalismo, realizado em São Luís, Maranhão, em novembro de 2010.

4 Silva (2008) baseia suas reflexões no mapeamento, realizado por Hohlfeldt e Strelow (2007), das metodologias adotadas nos trabalhos apresentados no núcleo de Jornalismo dos congressos da Intercom de 1998 a 2007. O levantamento indica a Análise de Discurso como a metodologia mais recorrente nos artigos, seguida pela Análise de Conteúdo. Juntas, essas duas estratégias metodológicas (contabilizando tanto as explicitadas quanto às inferidas) totalizam cerca da metade das ocorrências de métodos. É preciso destacar que, em alguns trabalhos, identificou-se mais de uma metodologia. 
5 Silva afirma que o trato com textos jornalísticos é mais vantajoso em todos os quesitos: "acesso ao objeto de trabalho - é mais viável gravar telejornais e radiojornais, guardar exemplares de revistas, recortar jornais impressos ou arquivar páginas da internet do que conseguir autorização das empresas para se pesquisar dentro das redações ou mesmo a disponibilidade dos profissionais para entrevista e do que também entrevistar leitores; custos da pesquisa - é mais barato investigar produtos do que processo de produção ou modos de recepção, posto que muitos dos resultados divulgados em congressos ou publicados são fruto de trabalho individual e não do de equipes; tempo de duração da pesquisa trabalhos que resultam de dissertações e teses ou que envolvam pesquisadores de diferentes instituições e/ou contam com fomento costumam trazer investigações com procedimentos metodológicos mais múltiplos ou mesmo investidos em mais de uma instância do processo jornalístico" (2008, p. 6-7).

6 Concebido dentro da tradição dos Estudos Culturais, o circuito é pensado para explicar a dinâmica entre produção, circulação e consumo de produtos culturais simbólicos. Sua representação esquemática circular resume-se basicamente em (1) produção (2) textos (3) leituras (4) culturas vividas (1) produção (2) textos... Para Johnson (2000), o circuito só pode ser entendido em sua complexidade se cada uma dessas etapas forem analisadas separadamente e relacionadas umas com as outras.

7 Para Guerra (2000), o objeto jornalismo pode ser analisado ainda pelo fator pragmático, associado ao sentido e à finalidade da atividade jornalística, isto é, ao compromisso dos jornalistas com seu público.

8 O exemplo dado por Guerra para explicar a dimensão técnico-procedimental ajuda a elucidar esse ponto: "se num conflito as partes envolvidas devem ser ouvidas igualmente, o modo como 'concretizar' essa orientação é tarefa de uma técnica que orienta os procedimentos: pode-se ouvir as partes numa mesma edição, ou pode-se primeiro publicar a denúncia e, na edição seguinte, garante-se o mesmo espaço e destaque ao acusado para sua defesa" (2000, p. 4). Como definir, com base no produto, se o jornalista/ veículo ouviu as duas fontes em momentos diferentes ou para uma mesma edição por motivações éticas, políticas, econômicas ou por falta de opção? Responder com propriedade esta pergunta baseando-se no texto exigiria uma incursão na análise discursiva.

9 Ponte (2005) propõe um Protocolo de Análise de Conteúdo detalhado para investigar a construção da infância pelo discurso jornalístico. Embora apóie-se apenas em variáveis temáticas e formais e concentrese no estudo da mensagem, o roteiro elaborado pela autora ajuda a pensar o protocolo de análise de cobertura jornalística.

10 Entre outros critérios possíveis de classificação estão os sugeridos por Sousa (2004): (1) segundo a proveniência (externas ao veículo, internas ou mistas), (2) segundo o índice de pró-atividade (ativas ou passivas), (3) segundo o estatuto (oficiais estatais, oficiais não-estatais, oficiosas ou informais), (4) segundo a frequência das contribuições (estáveis/permanentes ou pontuais/circunstanciais), (5) segundo a origem geográfica (locais, regionais, nacionais ou internacionais); e por Lage (2001), que divide as fontes em (6) oficiais, oficiosas ou independentes, (7) primárias ou secundárias e (8) testemunhas ou experts.

11 As informações podem ser atribuídas a uma instituição, instância do poder público ou pessoa específica quando são extraídas, por exemplo, de sites e blogs oficiais ou de redes sociais comprovadamente mantidas pela fonte em questão (caso do Twitter, Facebook, Orkut, entre outros). 